\title{
ACMG technical standards and guidelines for genetic testing for inherited colorectal cancer (Lynch syndrome, familial adenomatous polyposis, and MYH-associated polyposis)
}

\author{
Madhuri Hegde, $\mathrm{PhD}^{1}$, Mathew Ferber, $\mathrm{PhD}^{2}$, Rong Mao, $\mathrm{PhD}^{3}$, Wade Samowitz, $\mathrm{MD}^{3}$ and Arupa \\ Ganguly, PhD'; a Working Group of the American College of Medical Genetics and Genomics \\ (ACMG) Laboratory Quality Assurance Committee
}

\begin{abstract}
Disclaimer: These American College of Medical Genetics and Genomics standards and guidelines are developed primarily as an educational resource for clinical laboratory geneticists to help them provide quality clinical laboratory genetic services. Adherence to these standards and guidelines is voluntary and does not necessarily ensure a successful medical outcome. These standards and guidelines should not be considered inclusive of all proper procedures and tests or exclusive of other procedures and tests that are reasonably directed toward obtaining the same results. In determining the propriety of any specific procedure or test, the clinical laboratory geneticist should apply his or her own professional judgment to the specific circumstances presented by the individual patient or specimen. Clinical laboratory geneticists are encouraged to document in the patient's record the rationale for the use of a particular procedure or test, whether or not it is in conformance with these standards and guidelines. They also are advised to take notice of the date any particular guideline was adopted and to consider other relevant medical and scientific information that becomes available after that date. It also would be prudent to consider whether intellectual property interests may restrict the performance of certain tests and other procedures.
\end{abstract}

Lynch syndrome, familial adenomatous polyposis, and Mut Y homolog (MYH)-associated polyposis are three major known types of inherited colorectal cancer, which accounts for up to $5 \%$ of all colon cancer cases. Lynch syndrome is most frequently caused by mutations in the mismatch repair genes $M L H 1, M S H 2, M S H 6$, and PMS2 and is inherited in an autosomal dominant manner. Familial adenomatous polyposis is manifested as colonic polyposis caused by mutations in the APC gene and is also inherited in an autosomal dominant manner. Finally, MYHassociated polyposis is caused by mutations in the MUTYH gene and is inherited in an autosomal recessive manner but may or may not be associated with polyps. There are variants of both familial adenomatous polyposis (Gardner syndrome-with extracolonic features-and Turcot syndrome, which features medulloblastoma) and Lynch syndrome (Muir-Torre syndrome features sebaceous skin carcinomas, and Turcot syndrome features glioblastomas). Although a clinical diagnosis of familial adenomatous polyposis can be made using colo- noscopy, genetic testing is needed to inform at-risk relatives. Because of the overlapping phenotypes between attenuated familial adenomatous polyposis, MYH-associated polyposis, and Lynch syndrome, genetic testing is needed to distinguish among these conditions. This distinction is important, especially for women with Lynch syndrome, who are at increased risk for gynecological cancers. Clinical testing for these genes has progressed rapidly in the past few years with advances in technologies and the lower cost of reagents, especially for sequencing. To assist clinical laboratories in developing and validating testing for this group of inherited colorectal cancers, the American College of Medical Genetics and Genomics has developed the following technical standards and guidelines. An algorithm for testing is also proposed.

Genet Med advance online publication 5 December 2013

Key Words: colorectal cancer; familial adenomatous polyposis; Lynch syndrome; MYH-associated polyposis

\section{INTRODUCTION}

Colorectal cancer (CRC) can be characterized as sporadic, familial, or hereditary. The American Cancer Society expects 142,000 new cases of CRC in 2013. It is estimated that 20-30\% of all CRCs are familial, which includes CRCs of multifactorial inheritance. CRCs due to inherited highly penetrant single-gene mutations may account for an additional $5 \%$ of all colon cancer cases. ${ }^{1,2}$

Of the three major types of inherited CRC, Lynch syndrome-which was previously known as hereditary nonpolyposis CRC-is typically recognized as an assemblage of associated cancers characterized by defective mismatch repair (MMR) leading to microsatellite instability (MSI).
Lynch syndrome is most frequently caused by mutations in the MMR genes MLH1, MSH2, MSH6, and PMS2 and is inherited in an autosomal dominant manner. Familial cases that meet the Amsterdam criteria but wherein tumors show MSI-low or MSI-stable profiles and have no mutation in the MMR genes are now classified as familial CRC type X, which is likely to be a heterogeneous collection of disorders. ${ }^{1}$ Familial adenomatous polyposis (FAP) is manifested as extensive colonic polyposis caused by mutations in the APC gene and inherited in an autosomal dominant manner. Lastly, in 2002, an autosomal recessive condition, $\mathrm{MYH}$-associated polyposis (MAP), caused by mutations in the MUTYH gene, 
was described. ${ }^{3}$ Lynch syndrome and FAP have sometimes also been referred to as Gardner syndrome (FAP with extracolonic features), Muir-Torre syndrome (Lynch syndrome with sebaceous skin lesions), and Turcot syndrome (FAP with medulloblastomas or Lynch syndrome with glioblastomas). Clinical testing for these genes has progressed rapidly in the past few years with advances in technologies and the lower cost of reagents, especially for sequencing., ${ }^{4,5}$

The guidelines in this document are limited to inherited CRCs only. The Evaluation of Genomics Applications in Practice and Prevention Working Group has published recommendations for genetic testing strategies in newly diagnosed individuals with CRC. The Evaluation of Genomics Applications in Practice and Prevention Working Group found sufficient evidence to recommend screening all newly diagnosed patients with CRC for Lynch syndrome to prevent morbidity and mortality in their at-risk relatives. The Working Group found that measurements of clinical validity varied with each test and strategy. Although several testing strategies were potentially effective, none was clearly superior. A follow-up study found that immunohistochemistry (IHC) with reflex to serine/threonine-protein kinase B-Raf $(B R A F)$ testing was the most cost-effective method of universal screening for Lynch syndrome. ${ }^{6,7}$ This strategy can identify a significant number of Lynch syndrome patients. ${ }^{8-10}$

A description of genomic sequence and a listing of mutations and single-nucleotide polymorphisms (SNPs) for genes is provided in this document. The entire genomic sequence along with the structural motifs of the genes described in this document can be found at http://www.genome.ucsc.edu. A listing of mutations can be found in the Human Gene Mutation Database at http://www.hgmd.cf.ac.uk/ac/search.php and the InSight database at http://www.insight-group.org. SNPs are listed in http://www.ncbi.nih.gov/dbSNP (build 135) and the University of California Santa Cruz Genome Browser (http:// www.genome.ucsc.edu).

\section{LYNCH SYNDROME, PREVIOUSLY TERMED HEREDITARY NONPOLYPOSIS CRC}

Lynch syndrome is the most common form of inherited CRC. This syndrome is an autosomal dominant disease with a population incidence of $\sim 1$ in $4-500$ and is responsible for $~ 3 \%$ of all colon cancer cases. Lynch syndrome is characterized by genetic heterogeneity and is known to be associated with mutations in at least four MMR genes: MLH1, MSH2, MSH6, and PMS2.

\subsection{Gene symbol/chromosome locus, OMIM, and transcript number}

Lynch syndrome (OMIM 120435) is a genetically heterogeneous disease caused by mutations in the following MMR genes:

MLH1: MutL, Escherichia coli, homolog of, 1; located on chromosome 3p21.3 (OMIM:120436), NM_000249.5 MSH2: MutS, E. coli, homolog of, 2; located on chromosome 2p22-p21 (OMIM:609309), NM_000251.1
MSH6: MutS, E. coli, homolog of, 6; located on chromosome 2p16 (OMIM:600678), NM_000179.2

PMS2: Postmeiotic segregation increased Saccharomyces cerevisiae, 2; located on chromosome $7 \mathrm{p} 22$ (OMIM:600259), NM_000535.5

\subsection{Other loci}

PMS1: Postmeiotic segregation increased S. cerevisiae, 1; located on chromosome 2q31-q33 (OMIM:600258)

TGFBR2: Transforming growth factor- $\beta$ receptor, type II; located on chromosome 3p22 (OMIM:190182)

MLH3: MutL, E. coli, homolog of, 3; located on chromosome 14q24.3 (OMIM:604395)

EpCAM: Also known as TACSTD1, located on chromosome 2p21 (OMIM:185535)

BRAF: Located on chromosome 7q34 (OMIM:164757)

\subsection{Brief clinical description}

Patients with Lynch syndrome have up to an $80 \%$ lifetime risk of developing colon cancer and, in women, up to a $60 \%$ lifetime risk of developing endometrial carcinoma. Affected individuals are also at greater risk for other cancers, such as stomach, ovarian, small-bowel, biliary, renal pelvis, and ureteral cancers. In contrast to patients with FAP, patients with Lynch syndrome develop adenomas at a normal rate, but these precursor lesions progress more rapidly through the stages of carcinogenesis. Relative to sporadic CRC, adenomas and carcinomas in Lynch syndrome occur more often in the proximal colon. ${ }^{11-14}$

The average age of onset for CRC in Lynch syndrome is 61 years. The age of diagnosis of Lynch syndrome-associated endometrial cancer is 46-62 years. Lynch syndrome-associated ovarian cancers have an age of onset of $\sim 42$ years, and $30 \%$ of individuals with a diagnosis of ovarian cancer are diagnosed by the age of 40 . Among women with Lynch syndrome who develop both colon and endometrial cancers, 50\% present first with endometrial cancer. ${ }^{11,13,15,16}$

The clinical diagnosis of Lynch syndrome has historically been based on the Amsterdam criteria, although the revised Bethesda criteria are commonly used. ${ }^{17-19}$ In 1990, the Amsterdam criteria were initially developed as a research tool to enrich for a more homogeneous population, but when used clinically, these criteria identify only $\sim 60 \%$ of patients with Lynch syndrome..$^{20,21}$ This lack of sensitivity led to the development of the revised criteria (Amsterdam II Criteria), which take into account the presence of extracolonic cancers and have a detection sensitivity of $\sim 80 \% .^{22}$ The Bethesda Guidelines were developed by the National Cancer Institute to advise on the testing of tumors for MSI when CRC occurred before the age of 50 , when a synchronous or metachronous colon cancer or other related cancer was present, and when there was a significant family history. ${ }^{23,24}$

\subsection{Mode of inheritance}

Lynch syndrome is inherited in an autosomal dominant manner. The majority of Lynch syndrome patients inherit a mutation in 
one of the MMR genes from a parent; however, cancer development is variable with regard to age, and the mutation may show incomplete penetrance. De novo mutations have been recently reported with a mutation rate of $\sim 1.6 \% .{ }^{25}$ Rare biallelic MMR mutations have been reported in the $\mathrm{MLH1}, \mathrm{MSH} 2, \mathrm{MSH}$, and PMS2 genes, and this leads to a more severe phenotype known as constitutional MMR deficiency. ${ }^{26,27}$

\subsection{Gene description/normal gene product}

\subsubsection{MLH1 gene}

The MLH1 gene is 72,558 bases in length and consists of 19 coding exons; the translated protein contains 756 amino acids. The protein MLH1 dimerizes with the protein product of the PMS2 gene to coordinate the binding of other proteins involved in MMR, including the helicases, the protein encoded by EXO1, proliferating cell nuclear antigen, single-stranded DNA-binding protein (Replication protein A, RPA), and DNA polymerases.

\subsection{2 $\mathrm{MSH} 2$ gene}

The MSH2 gene is 159,343 bases in length and consists of 16 coding exons; the translated protein contains 934 amino acids. The MSH2 protein forms a heterodimer with either MMR protein MSH6 or MSH3 and functions to identify mismatches. A sliding clamp model has been put forward to describe the structure of the heterodimer. Mismatches in the DNA are thought to be detected as the clamp slides along the DNA.

\subsubsection{MSH6 gene}

The MSH6 gene is 23,871 bases in length and consists of 10 coding exons; the translated protein contains 1,360 amino acids. The MSH6 protein forms a heterodimer with the DNA MMR protein MSH2 and functions in the identification of mismatches by a sliding clamp model.

\subsubsection{PMS2 gene}

The PMS2 gene is 35,887 bases in length and consists of 15 coding exons; the translated protein contains 862 amino acids. The PMS2 protein dimerizes with the MLH1 protein (see MLH1 for details on the function of this protein dimer). The PMS2 gene has at least 15 pseudogenes, which have a significantly high homology with the active gene. ${ }^{28}$

\subsection{Function of MMR genes}

MMR genes are involved in numerous cellular functions, including the following:

1. Repairing DNA synthesis errors;

2. Repairing double-stranded DNA breaks;

3. Apoptosis;

4. Antirecombination;

5. Destabilization of DNA.

These responsibilities make MMR proteins extremely important in the basic maintenance of the genetic material and regulation of the cellular cycle. When MMR is lost or is defective, there is a decrease in apoptosis and an increase in cell survival. This can provide a selective growth advantage to the cell, thereby causing a greater susceptibility to tissue-specific cancers.

\subsection{Mutational mechanism/abnormal gene product}

Approximately $50 \%$ of the mutations are in the $M L H 1$ gene and $40 \%$ are in the MSH2 gene. Mutations in MSH6 account for $~ 7-10 \%$ of families with Lynch syndrome, and mutations in PMS2 are responsible for $<5 \%$ of Lynch families. About $1-3 \%$ of mutations are in the EPCAM gene. The contribution of mutations from MSH6, PMS2, and EpCAM genes is an estimate, and different studies have reported varying numbers. These genes cooperatively participate to repair nucleotide mismatch errors arising in DNA replication, and deficiencies in any one of the repair genes can lead to Lynch syndrome. In the somatic tumor tissue, mutations in the MMRs genes result in high levels of MSI. ${ }^{29-34}$

\subsection{Mutation spectrum, prevalence, and ethnic association} of common mutations

Mutations in the MMR genes have been observed in all ethnic groups. More than 2,000 different mutations (Human Gene Mutation Database, http://www.hgmd.org) have been identified in the four MMR genes: 875 in the MLH1 gene, 860 in the MSH2 gene, 290 in the MSH6 gene, and 111 in the PMS2 gene. Mutations can be of the missense, nonsense, splice site, or regulatory types. Large deletions are also responsible for $5-10 \%$ of $M L H 1$ gene mutations. Large deletions appear to be especially common in the $\mathrm{MSH} 2$ gene, where they reportedly account for $17-50 \%$ of mutations. Large deletions and duplications are rarely seen in MSH6 or PMS2 (MMR sequence variant database, http://www.med.mun.ca/mmvariants/). There are few mutation hotspots. The splice site mutation in intron 5 of the $\mathrm{MSH} 2$ gene, c. $942+3 \mathrm{~A}>\mathrm{T}$, has been repeatedly seen in different ethnicities, including Caucasians, African Americans, and Asians. A deletion of exon 16 in $M L H 1$ is a founder mutation detected in 29 families in Finland, and a deletion of exons 1-6 in MSH2 is a founder mutation in 18,981 individuals in the United States. The p.A636P mutation in the MSH2 gene has been found in $0.59 \%$ of the Ashkenazi Jewish population with CRC..$^{35}$

\subsection{Testing criteria}

Individuals meeting any of the following revised Bethesda criteria $^{23}$ are recommended for MSI testing:

1. CRC diagnosed before age 50;

2. Presence of synchronous or metachronous CRC or other hereditary nonpolyposis CRC-related tumor, regardless of age;

3. $\mathrm{CRC}$ in an individual younger than 60 years of age exhibiting tumor-infiltrating lymphocytes;

4. CRC at any age, plus CRC or hereditary nonpolyposis CRC-related tumor diagnosed before the age of 50 years in at least one first-degree relative; 
5. CRC at any age, plus CRC or hereditary nonpolyposis CRC-related tumor diagnosed before the age of 50 years in two or more first- or second-degree relatives

\subsection{Algorithm for testing}

A suggested algorithm for Lynch syndrome testing is shown in Figure 1. This algorithm takes advantage of certain molecular features of a tumor to determine whether it is likely to be associated with Lynch syndrome and then how best to proceed with the germ line analysis.

\subsubsection{MSI analysis}

Because nearly all CRCs associated with Lynch syndrome exhibit MSI, the first step is to test the tumor (usually a CRC) for MSI either directly by PCR of microsatellite repeats and/or by IHC. ${ }^{36-38}$ Although usually concordant, discordant results from these two techniques are possible. For example, a missense mutation may destroy the function of an MMR protein without affecting its antigenicity, thus leading to an abnormal MSI result and a normal IHC result. Conversely, it is possible that some MMR-deficient tumors, such as endometrial cancers or colonic adenomas, may not have accumulated sufficient replication errors to be detected by PCR of microsatellite repeats; in those cases, IHC may show an abnormal result, whereas PCR may not. In addition, some tumors associated with the MSH6 germ line mutation have been reported to be microsatellite stable by PCR. ${ }^{39,40}$ Approximately $5 \%$ of cases that demonstrate MSI have normal IHC for all proteins. Therefore, an abnormal result with either test should probably trigger the next set of tests in the algorithm, and consideration should be given to performing both tests, especially if the index of suspicion for Lynch syndrome is high. In addition, the IHC results can be used to guide the germ line analysis (see below) and determine whether or not BRAF or MLH1 promoter methylation testing should be performed.

\subsubsection{Methylation of the MLH1 promoter "region C"}

Approximately $10-15 \%$ of sporadic CRCs also exhibit MSI. The molecular basis for instability in these tumors is most often methylation of the MLH1 promoter, leading to loss of both mRNA and protein expression. ${ }^{41-49}$ MLH1 promoter

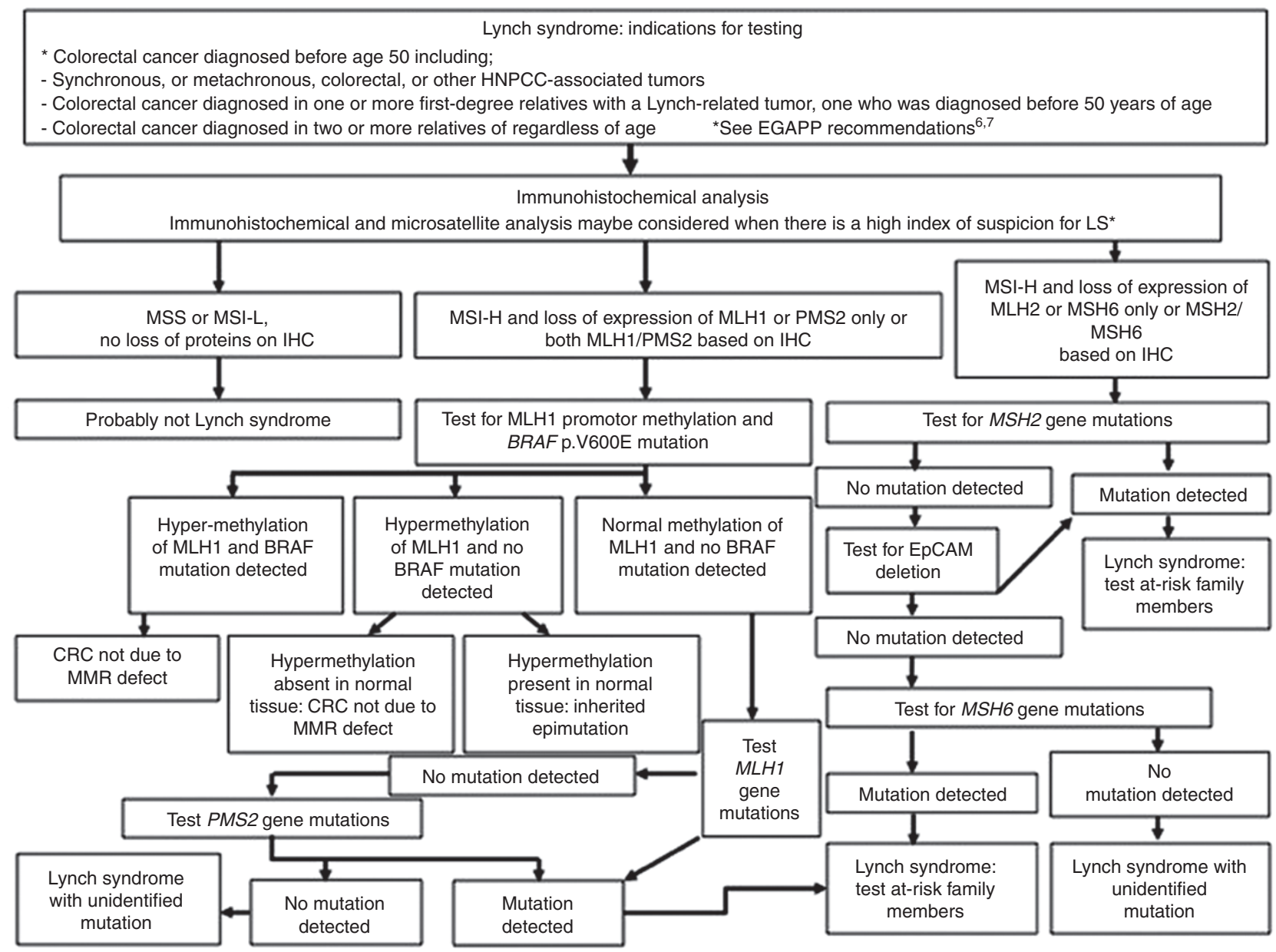

Figure 1 Lynch syndrome: indications for testing. CRC, colorectal cancer; EGAPP, Evaluation of Genomics Applications in Practice and Prevention Working Group; HNPCC, hereditary non-polyposis colorectal cancer; IHC, immunohistochemistry; LS, Lynch syndrome, MMR, mismatch repair; MSI-H, microsatellite instability-high; MSI-L, microsatellite instability-low; MSS, microsatellite-stable. 
region " $\mathrm{C}$ " is a small proximal region $(-248$ to -178 relative to the transcription start site) in which the methylation status invariably correlates with the lack of MLH1 expression. The typical IHC profile of one of these sporadic unstable tumors is loss of expression of both MLH1 and PMS2. This is because the stability of PMS2 depends on its ability to form a complex with MLH1 (a similar situation exists with MSH2 and MSH6). The converse, however, is usually not true because tumors with defects in PMS2 or MSH6 may maintain expression of MLH1 or MSH2, respectively. A tumor with loss of MLH1 and PMS2 may be either sporadic or associated with Lynch syndrome because either promoter methylation or a germ line mutation in MLH1 will lead to this same IHC profile. A way to distinguish between these two possibilities is desirable, so as to avoid unnecessary germ line analysis of patients with ${ }^{50,51}$ sporadic tumors. It must be noted that germ line MLH1 hypermethylation, although rare, has been documented..$^{52,53}$

\subsubsection{BRAF gene mutation p.V600E}

More than half of sporadic MSI tumors (50-68\%) have a specific mutation in the BRAF gene, p.V600E, which is rarely detected in Lynch syndrome-associated cancers. ${ }^{41,43,54}$ Therefore, if an unstable tumor harbors the BRAF gene p.V600E mutation, it is most likely sporadic and germ line testing is not necessary. If the BRAF mutation is not present, then the tumor may be either sporadic or associated with Lynch syndrome.

\subsubsection{MMR protein expression}

Lack of expression of MSH2, MSH6, or PMS2 (with maintenance of MLH1 expression) is usually not seen in sporadic unstable tumors, and proceeding to germ line testing should be based on these IHC profiles. The IHC profile can also be used to choose the gene(s) of interest for germ line evaluation. In cases in which only one gene product is not expressed (typically MSH6 or PMS2), then that gene can be evaluated. If two gene products are not expressed (usually MLH1/PMS2 or MSH2/MSH6), then either MLH1 or MSH2 is the likely culprit, and molecular analysis can begin for one of those genes. Simultaneous evaluation of both genes that form a complex can also be considered because the interplay of gene inactivation, complex stability, and IHC expression may not always be predictable.

A germ line evaluation without MSI or IHC tumor testing can be justified in cases with a high enough index of suspicion for Lynch syndrome (e.g., a very strong family history of Lynch syndrome-associated tumors occurring at young ages), when tumor is not available for MSI or IHC, or when the family history is suspicious for Lynch syndrome and the consultand is cancer free. Because the screening tests described above may not be perfect, with a high enough index of suspicion a germ line evaluation should be performed regardless of the results of the screening tests. IHC results may still be helpful in guiding the germ line evaluation and, perhaps, help in determining the relevance of amino acid changes of uncertain significance.

\subsection{Sensitivity and specificity}

A combination of Sanger sequencing and deletion detection can detect $>80 \%$ of mutations in $M L H 1$ and $M S H 2$ genes. The detection rate is unknown for MSH6 and PMS2 genes.

\subsection{Diagnostic versus predictive testing}

Molecular testing for mutations in MMR genes is used for confirmative diagnosis..$^{55}$ Positive results are considered diagnostic of Lynch syndrome. Penetrance of colon cancer associated with mutations in MMR genes is less than $100 \%$. Therefore, some individuals with a cancer-predisposing mutation in one of the MMR genes may never develop colon cancer. ${ }^{5,56,57}$

\subsection{Guidelines for detection of mutations in the MMR genes: methods}

All general guidelines for PCR and DNA sequencing in the American College of Medical Genetics and Genomics (ACMG) Standards and Guidelines for Clinical Genetics Laboratories apply (http://www.acmg.net). The following additional details are specific for MMR gene testing. For this test, there are two valid methods with different strengths and weaknesses.

\subsubsection{Sample requirements and processing}

Normal and tumor tissues are required to perform MSI and IHC testing. Either fresh-frozen tissue or formalin-fixed paraffin-embedded (FFPE) tissue block can be used. The freshfrozen or the FFPE tissue block should be carefully chosen. It is preferable that it contain adequate normal and tumor tissues. The tissue is sectioned and used for hematoxylin and eosin staining, which is used to identify the boundaries of the normal and tumor tissues. Once the sections are obtained $(\sim 3-5 \mu \mathrm{m})$, IHC can be performed, and DNA can be extracted for MSI. DNA extracted from a blood sample can also be used as a representative normal tissue from the patient.

For mutation detection in the MMR genes via Sanger sequencing, DNA extracted from FFPE tissue can be used, except for the PMS2 gene, because the quality of DNA obtained from FFPE tissue is compromised. DNA extracted from a blood sample is required for MMR gene sequencing. Refer to ACMG Standards and Guidelines for Clinical Genetics Laboratories, Section G3, for technical details.

\subsubsection{IHC}

IHC is performed on all four MMR proteins: MLH1, MSH2, MSH6, and PMS2. It is necessary to analyze the expression of all four relevant MMR proteins because loss of either MSH6 or PMS2 may occur and because assessment of only MLH1 and MSH2-or only MLH1, MSH2, and MSH6 (as is performed in some laboratories)-may miss abnormalities in expression.

The tissue sections are incubated with monoclonal antibodies against MLH1, MSH2, MSH6, and PMS2. All sections are examined for expression of MMR proteins in the nucleus and adjacent nonneoplastic tissue elements and subsequently defined as showing presence or absence of these proteins. 


\subsubsection{DNA extraction}

DNA extractions from fresh tissue or FFPE sections can be performed using routine DNA extraction methods after pretreatment of the tissue sections as described in section 2.13.1. The sections are deparaffinized with xylene and enzymatically digested with proteinase $\mathrm{K}$ for tissue dissolution. The digested sections (DNA lysates) can be directly used for MSI testing, or DNA can be extracted using standard DNA extraction methods using glycogen as a carrier to enhance yield. ${ }^{58}$

\subsubsection{BRAF gene p.V600E missense mutation}

The p.V600E mutation can be detected using a targeted mutation detection technique, such as restriction enzyme digestion, allele-specific primer extension, or real-time PCR. Refer to ACMG Standards and Guidelines for Clinical Genetics Laboratories, Section G8.7, for technical details.

\subsubsection{MLH1 promoter methylation region "C"}

Bisulfite modification with real-time (quantitative) methylation-specific PCR analysis to detect the methylated and unmethylated allele is the commonly used method. ${ }^{59-64}$ The first step of the methylation-specific PCR procedure is chemical conversion of DNA by sodium bisulfite. Genomic DNA is treated with sodium bisulfite, which deaminates unmethylated cytosines to uracil. 5-Methyl cytosines are resistant to this deamination and following sodium bisulfite treatment will remain as cytosines. After desulfonation and purification, the DNA is used as a template in a real-time TaqMan PCR reaction with amplification primers that are designed to avoid cytosines in CpG dinucleotides. This allows for the equivalent amplification of both methylated and unmethylated alleles. During PCR amplification, different fluorescently labeled TaqMan probes are used to discriminate between methylated and unmethylated DNA sequences by recognizing either cytosine or uracil (thymine) if the sample DNA was methylated or unmethylated, respectively. By interpolation on standard curves, generated by titration of a sample from an unaffected individual, the amount of methylated and unmethylated DNA can be determined. A methylation index, defined as the amount of methylated DNA divided by methylated plus unmethylated DNA, can be calculated. Deviation from a predetermined normal range established by the laboratory would be indicative of disease. Refer to ACMG Standards and Guidelines for Clinical Genetics Laboratories, Section G8.7, for technical details.

\subsubsection{Methods for MSI determination}

Methods for MSI determination by PCR have already been described (refer to ACMG Standards and Guidelines for Clinical Genetics Laboratories, Section G9, for technical details). With respect to PCR, the National Cancer Institute panel of microsatellite repeats, BAT25, BAT26, D2S123, D17S250, and D5S346, can be used. Most laboratories are using a commercially available five-marker mononucleotide or quasimonomorphic panel. A quasimonomorphic panel consisting of BAT25, BAT26, NR21, NR22, NR24, and other microsatellite repeats has also been described (Table 1). ${ }^{17,65-68}$ If $30 \%$ or more of the repeats are unstable, a tumor is classified as MSI-high (MSI-H). If fewer than $30 \%$ of repeats are unstable, a tumor is classified as MSIlow (MSI-L), and if no repeats are unstable, a tumor is classified as microsatellite stable. A MSI-L profile does not appear to be a good predictor of Lynch syndrome, so this result is grouped with the microsatellite-stable (MSS) type and does not lead to further testing. The most widely used microsatellite panel at this time is probably the Bethesda consensus panel, a combination of two mononucleotide repeats and three dinucleotide repeats (NCI panel). The quasimonomorphic panel consists of five mononucleotide repeats, and it appears that the two panels are highly concordant with respect to the designation of high degrees of MSI. ${ }^{66-70}$ Instability in the mononucleotide repeat BAT26 correlates very well with high degrees of tumor instability, especially with respect to sporadic unstable tumors; however, it is recommended that BAT26 not be used by itself in the evaluation of potential Lynch syndrome-affected individuals because BAT26 stability has been reported in some Lynch syndrome-associated microsatellite unstable tumors, especially those with large $\mathrm{MSH} 2$ deletions. It has also been shown that both BAT25 and BAT26 in 28\% of African Americans can be polymorphic at one of the loci and therefore could be incorrectly classified as MSI positive. ${ }^{38,69}$

2.13.7 Detection of point mutations in the MMR genes: methods for PCR

2.13.7.1 PCR method. Several sets of primers, PCR conditions, and methods of separation and detection have been published. Other primers and methods can be used if equivalence is demonstrated. ${ }^{39,71}$

2.13.7.2 Primer design. All PCR reactions, for any locus, can theoretically fail to detect an allele if there is a polymorphism at a primer-binding site. The dbSNP database build 135 (http:// www.ncbi.nih.gov/dbSNP) and the 1000 Genomes mutation database update the SNPs in the human genome on a regular basis. It is important that laboratories check for the presence of SNPs under primers minimally on an annual basis.

2.13.7.3 PCR product. Patient amplicon sizes should be determined by running the PCR products on an agarose gel using a 100-bp standard ladder.

2.13.8 Methods for mutation detection by scanning the MMR genes

Historically, mutational evaluation of MMR genes was accomplished using a scanning method such as single-strand conformation polymorphism, conformation strand gel electrophoresis, denaturing gradient gel electrophoresis, or denaturing highpressure liquid chromatography, followed by Sanger sequencing of aberrant amplicons. In addition, other scanning techniques, such as temperature-gradient capillary electrophoresis and mutation scanning by high-resolution melting analysis, have also been used. Sanger sequencing of all coding exons of the MMR genes is now considered the gold standard for mutation detection. An important aspect of mutational evaluation 
is the detection of relatively large deletions of an exon or more. Such deletions are not uncommon, especially in the MSH2 gene, and will not be detected by sequencing because the nondeleted allele will still be amplified. Refer to ACMG Standards and Guidelines for Clinical Genetics Laboratories, Section G11, for technical details.

\subsubsection{Methods for sequencing}

2.13.9.1 Sanger sequencing. PCR amplification is performed on all coding exons and intron/exon boundaries of the relevant MMR gene(s) MLH1, MSH2, MSH6, and PMS2 in patients' genomic DNA. IHC or IHC and MSI results together may help to narrow down the sequencing to one or two genes of the MMR complex. Due to the high homology of the PMS2 functional gene and pseudogenes, it is difficult to find PCR and/ or sequencing primer-binding sites that allow amplifying and sequencing of only the functional gene (see Supplementary Tables S1-S4 online for PCR conditions). ${ }^{72}$ Long-range PCR using functional gene-specific primers can overcome this problem. Refer to ACMG Standards and Guidelines for Clinical Genetics Laboratories, Section G10, for technical details. ${ }^{73,74}$

2.13.9.2 Next-Generation Sequencing. The cost of next-generation sequencing (NGS) has dropped rapidly in the past 2 years, and it is now possible to sequence all genes implicated in CRC in a panel for a lower cost than that for doing Sanger sequencing. NGS can be used to sequence all four genes using

Table 1 Microsatellite markers for microsatellite instability

\begin{tabular}{|c|c|c|c|c|c|}
\hline \multirow[b]{3}{*}{ Marker name } & Primer sequence & \multirow[b]{3}{*}{ Chromosome } & \multirow{3}{*}{$\begin{array}{c}\text { Gene near } \\
\text { marker }\end{array}$} & \multirow[b]{3}{*}{ Repeat size } & \multirow{3}{*}{$\begin{array}{l}\text { Allele size } \\
\text { range (bp) }\end{array}$} \\
\hline & \multirow{2}{*}{$\begin{array}{l}\text { Forward (fluorescently labeled) } \\
\text { Reverse }\end{array}$} & & & & \\
\hline & & & & & \\
\hline \multicolumn{6}{|c|}{$\mathrm{NCl}$ panel markers ${ }^{44}$} \\
\hline \multirow[t]{2}{*}{ BAT-25 } & VIC 5'-TCG CCT CCA AGA ATG TAA GT & $4 q 11-12$ & C-Kit & Mononucleotide & $110-130(122)$ \\
\hline & 5'-TCT GCA TTT TAA CTA TGG CTC & & & & \\
\hline \multirow[t]{2}{*}{ BAT-26 } & NED 5'-TGA CTA CTT TTG ACT TCA GCC & $2 p$ & MSH2 & Mononucleotide & $112-120(117)$ \\
\hline & 5'-AAC CAT TCA ACA TTT TTA ACC C & & & & \\
\hline \multirow[t]{2}{*}{ D2S123 } & VIC 5'-AAA CAG GAT GCC TGC CTT TA & $2 \mathrm{p} 16$ & MSH2 & Dinucleotide & $197-227$ \\
\hline & 5'-GGA CTT TCC ACC TAT GGG AC & & & & \\
\hline \multirow[t]{2}{*}{ D17S250 } & FAM 5'-GGA AGA ATC AAA TAG ACA AT & $17 q 11.2-q 12$ & BRCA1 & Dinucleotide & 130-170 \\
\hline & 5'-GCT GGCCAT ATA TAT ATT TAA ACC & & & & \\
\hline \multirow[t]{2}{*}{ D5S346 } & FAM 5'-ACT CAC TCT AGT GAT AAA TCG & $5 q 21$ & APC & Dinucleotide & $96-129$ \\
\hline & $5^{\prime}$ AGC AGA TAA GAC AGT ATT ACT AGT T & & & & \\
\hline \multicolumn{6}{|c|}{ Quasimonomorphic mononucleotide markers ${ }^{45}$} \\
\hline \multirow[t]{2}{*}{ BAT-25 } & NED 5'-TCG CCT CCA AGA ATG TAA GT & $4 q 11-12$ & C-Kit & Mononucleotide & $110-130(122)$ \\
\hline & 5'-TCT GCA TTT TAA CTA TGG CTC & & & & \\
\hline \multirow[t]{2}{*}{ BAT-26 } & 5'-TGA CTA CTT TTG ACT TCA GCC & $2 p$ & MSH2 & Mononucleotide & $112-120(117)$ \\
\hline & FAM 5'-AAC CAT TCA ACA TTT TTA ACC C & & & & \\
\hline \multirow[t]{2}{*}{ NR-21 } & 5'-TAA ATG TAT GTC TCC CCT GG & $14 q 11.2$ & SLC7A8 & Mononucleotide & 103 \\
\hline & VIC 5'-ATT CCT ACT CCG CAT TCA CA & & & & \\
\hline \multirow[t]{2}{*}{ NR-22 } & 5'-GAG GCT TGT CAA GGA CAT AA & $11 q 24-q 25$ & Transmembrane & Mononucleotide & 142 \\
\hline & FAM 5'-AAT TCG GAT GCC ATC CAG TT & & $\begin{array}{l}\text { precursor } \\
\text { protein B5 }\end{array}$ & & \\
\hline \multirow[t]{2}{*}{ NR-24 } & 5'-CCA TTG CTG AAT TTT ACC TC & $2 q 11.2$ & Zinc finger 2 & Mononucleotide & 132 \\
\hline & VIC 5'-ATT GTG CCA TTG CAT TCC AA & & (ZNF-2) & & \\
\hline \multicolumn{6}{|c|}{ Alternate panel markers ${ }^{46-48}$} \\
\hline \multirow[t]{2}{*}{ D18535 } & VIC 5'-AGC TAG ATT TTT ACT TCT CTG & $18 \mathrm{q} 21$ & DCC & Dinucleotide & $93-130$ \\
\hline & 5'-CTG GTT GTA CAT GCC TGA C & & & & \\
\hline \multirow[t]{2}{*}{ TP53-DI } & NED 5'-AGG GAT ACT ATT CAG CCC GAG GTG & $17 p 13$ & P53 & Dinucleotide & $95-140$ \\
\hline & 5'-ACT GCC ACT CCT TGC CCC ATT C & & & & \\
\hline \multirow[t]{2}{*}{ TP53-PENTA } & FAM 5'-ACT CCA GCC TGG GCA ATA AGA GCT & $17 p 13$ & P53 & Pentanucleotide & 105-150 \\
\hline & 5'-ACA AAA CAT CCC CTA CCA AAC AGC & & & & \\
\hline \multirow[t]{2}{*}{ D1S2883 } & VIC 5'-AAA TCT GGT CTT CTG TTT TCA CTA T & $1 \mathrm{q} 24$ & HPC1 & Dinucleotide & $170-220$ \\
\hline & 5'-TTC CAA ATG TTG ACT CTG C & & & & \\
\hline \multirow[t]{2}{*}{ FGA } & FAM 5'-GCC CCA TAG GTT TTG AAC TCA & $4 q 28$ & Fibrinogen alpha & Tetranucleotide & $160-230$ \\
\hline & 5'-TGA TTT GTC TGT AAT TGC CAG C & & & & \\
\hline
\end{tabular}

The markers recommended by the National Cancer Institute ${ }^{44}$ and quasimonomorphic markers ${ }^{45}$ are listed. 
target-enrichment methodologies such as digital PCR and insolution hybridization. The PMS2 gene cannot be sequenced using this technology due to the presence of pseudogenes (http://www.ucsc.edu). Target enrichment involves selection using a PCR-based method, such as highly multiplex PCR and digital PCR, or in-solution hybridization-based methods. Once the genes are selected, NGS can be performed using short- or long-read technologies. Data analysis is complex for NGS and requires significant bioinformatics input. The amount of data generated is large, and a major effort is required for annotation and variant classification.

It is important to note that all regions of interest (exons) may not be amenable to NGS, and some exons will have to be sequenced using Sanger sequencing to complete clinical testing. Furthermore, single-exon and multiexon deletions and duplications may not be detected and may require other methodologies. At this time, methylation analysis has not been adopted as a standard using NGS in clinical testing.

2.13.9.3 Sequence variation with unknown clinical consequences. Sequencing often reveals previously unreported and/ or uncharacterized variants. These variants can be missense mutations or a variation located within a splice site consensus sequence in which the contribution to disease cannot be predicted; these are reported as variants of uncertain significance. RNA analyses may be helpful to determine splicing defects. Following the recommendation from ACMG for interpretation of sequence variants, a missense mutation that leads to a nonconservative substitution of an evolutionarily conserved amino acid is more likely to be disease causing than a missense mutation that alters an amino acid that is not evolutionarily conserved. ${ }^{73}$ This classification should be approached with caution as more data from human genome sequencing and allele frequencies in different populations become available. Some variants may be rare polymorphisms in a particular population rather than disease-causing mutations. Family segregation studies may clarify the pathologic or benign nature of missense mutations.

\subsubsection{Methods for large gene rearrangements}

The two main methods to detect large deletions are Southern blot hybridization and multiplex ligation-dependent probe amplification (MLPA), with MLPA becoming more commonly used. Deletion of two or more sequential exons detected by MLPA is a fairly dependable result because each deleted exon can be considered confirmation of the other deleted exon(s). If only one exon is deleted, and no heterozygous polymorphism is detected by sequencing (especially under the probe), then a second confirmatory method is recommended. If MLPA is the original method used, then a Southern blot or quantitative PCR can be used as a confirmatory test. Other methods used for detection of large gene rearrangements include multiplex amplifiable probe hybridization and real-time (quantitative) PCR analysis. Refer to ACMG Standards and Guidelines for Clinical Genetics Laboratories, Section G11, for technical details.
2.13.10.1 Gene-targeted array-based comparative genomic hybridization (aCGH). Gene-targeted array-based comparative genomic hybridization $(\mathrm{aCGH})$ can be used to detect singleexon and multiexon deletions and duplications. ${ }^{75}$ This method is not dependent on a single probe and can be extremely sensitive because multiple probes are designed for each exon, thus avoiding allele dropout due to the presence of SNPs under probe, which is a major drawback of MLPA. Refer to ACMG Standards and Guidelines for Clinical Cytogenetics for technical details.

There are fewer concerns for contiguous deletion involving more than one exon; however, a confirmation is needed for a single-exon deletion detected by assays other than aCGH. A falsepositive result can be caused by a SNP under the primer, probe, or restriction endonuclease digestion site, which will affect the efficiency of the primer and/or probe annealing to the target or abolish a restriction enzyme digesting site. This is usually not a problem because sequencing will detect the polymorphism and indicate the presence of two alleles. Confirming a true positive typically involves performing another deletion detection assay. Possible deletion assays include Southern blot and an MLPA assay for the same gene, which uses different probes. A realtime (quantitative) PCR assay can also be used for this purpose. Using gene-targeted CGH arrays avoids any dropout because the detection of the deletion is based on multiple probes.

Searching the GenBank dbSNP database and selecting the primer and probe sites without any reported SNPs in the assay development can eliminate false positives. The SNP can be easily detected by sequencing that exon, or the single-exon deletion can be confirmed by secondary tests with the primers and then probing of a different sequence region than that in the primary test, e.g., a quantitative real-time (quantitative) PCR can be used as a confirmatory method.

\subsubsection{EpCAM deletion}

A common deletion in the $3^{\prime}$ region of the EpCAM gene causes somatic hypermethylation of MSH2 because the two genes are adjacent to each other on chromosome 2. Tumors arising from EpCAM gene deletion demonstrate an MSI-high profile and loss of MSH2 and/or MSH6 by IHC. ${ }^{76,77}$ Deletions in the $3^{\prime}$ region of the EPCAM gene can be detected using Southern blot, MLPA, or gene-targeted aCGH and should be analyzed in patients with IHC results showing loss of MSH2 and/or MSH6.

\subsection{Interpretation}

The following elements must be included in the report.

\subsubsection{MSI by PCR}

The panel of microsatellites analyzed, as well as the results from each locus, should be reported. An MSI-high profile is reported if $40 \%$ or more of the repeats are unstable; an MSI-stable profile is reported if no repeats are unstable, and an MSI-low profile is reported if fewer than $40 \%$ of repeats are unstable. Only a high degree of MSI is considered to be indicative of potential Lynch syndrome. 


\subsubsection{IHC results}

The results for antibody staining for all four MMR proteins (MLH1, MSH2, MSH6, and PMS2) should be reported as protein presence (normal staining), protein absence (negative staining), or uninterpretable. "Uninterpretable" refers to a lack of tumor staining without internal control positivity. Quantification of the strength of antibody staining is not recommended.

\subsubsection{Mutational testing of MMR genes}

The gene; mutation (nucleotide position); amino acid alteration, if present; deletion or insertion, if present; and transcript number should be reported. Changes should be classified as deleterious (pathogenic), benign, or a variant of uncertain significance. Refer to ACMG recommendations for standards for reporting and interpretation of sequence variation, revised in $2007 .^{73}$

Laboratories are strongly encouraged to deposit data from clinical sequencing into public databases such as ClinVar and other Leiden Open (source) Variation Database (LOVDs) (http:// www.ncbi.nlm.nih.gov/clinvar, http://www.hgvs.org) in order to update our understanding of genomic variants that will lead to enhanced patient care.

\section{FAMILIAL ADENOMATOUS POLYPOSIS}

FAP and several related colon cancer phenotypes are caused by mutations in the APC gene. The APC gene is a tumor suppressor gene, sometimes referred to as a "gatekeeper," that is responsible for regulating the Wnt pathway. In accordance with Knudson's two-hit hypothesis, both alleles of the APC gene are inactivated in tumors, resulting in loss of the functional protein. ${ }^{78} \mathrm{Germ}$ line mutations in the APC gene are responsible for FAP and have been well characterized. ${ }^{79}$ Identification of a germ line mutation in an affected individual is useful for confirmation of diagnosis and clinical management of presymptomatic family members.

\subsection{Gene symbol/chromosome locus, OMIM, and transcript number}

APC: Adenomatous polyposis coli; located on chromosome 5p22.2 (OMIM 611731), NM_000038.5

\subsection{Other loci}

None.

\subsection{Brief clinical description}

FAP is a heritable colon cancer predisposition disorder. FAP accounts for $1 \%{ }^{1}$ of all CRC. The disease is characterized by the presence of a large number of colorectal adenomatous polyps $(>100)$ that begin to form at a mean age of 16 years. Variable features include extracolonic polyps, dental abnormalities, congenital hypertrophy of the retinal pigment epithelium, soft tissue tumors, and desmoid tumors. FAP accompanied by nongastrointestinal maladies was historically referred to as Gardner syndrome before molecular evidence that Gardner syndrome and FAP are both due to mutations in the APC gene. Attenuated adenomatous polyposis (AFAP) is characterized by fewer colonic polyps (average of 30) and occurs later in life (average age of onset $\sim 40$ years). FAP, AFAP, and Gardner syndrome are caused by germ line mutations in the adenomatous polyposis coli cancer gene $(A P C)$.

\subsection{Mode of inheritance}

FAP is an autosomal dominant condition in which every affected individual has a $50 \%$ chance of passing on the disease allele to each of his/her offspring. Although APC gene mutations are inherited in an autosomal dominant manner, 20\% of FAP cases can have de novo germ line mutations in the APC gene. ${ }^{80,81}$ In addition, individuals without affected parents, and with or without affected siblings, can have adenomatous polyposis due to recessive inheritance of two mutations in the MUTYH gene (see section 4.4).

\subsection{Gene description/normal gene product}

The APC gene is $91 \mathrm{~kb}$ in length and encodes a transcript of $10.4 \mathrm{~kb}$. The protein product of this gene is $309 \mathrm{kD}$ long, with 2,843 amino acids, and has 15 exons. The protein belongs to the Wnt signal transduction pathway. Absence of functional APC gene product leads to aberrant transcription of c-myc, cyclin$\mathrm{D}$, and other target molecules. The normal gene product is also associated with cell adhesion and microtubule assembly.

\subsection{Mutational mechanism/abnormal gene product}

More than 1,500 different germ line mutations have been characterized in the APC gene (Human Gene Mutation Database, http://www.hgmd.org). The majority of mutations are point mutations, including nucleotide substitutions, deletions, or insertions, and most of them result in the introduction of a termination codon. Small subsets of missense mutations have been functionally characterized to have the potential to predispose to FAP. In addition, $20 \%$ of germ line mutations include gross deletions, insertions, and complex rearrangements.

\subsection{Mutation spectrum, prevalence, and ethnic association of common mutations}

Mutations in the APC gene have been observed in all ethnic groups.

\subsection{1 $A P C$ gene mutation spectrum}

The APC gene coding region consists of 15 exons, with exon 15 individually representing $\sim 6.5 \mathrm{~kb}$. The $5^{\prime}$ coding region of exon 15 includes a mutation cluster region, which is a common site of somatic mutations arising in tumors. Two recurrent mutations at codons 1061 and 1309 (located in the $5^{\prime}$ part of exon 15) account for $\sim 30 \%$ of germ line APC mutations (http://perso.curie.fr/Thierry.Soussi/APC.html; http://archive. uwcm.ac.uk/uwcm/mg/hgmd0.html; and http://life2.tau.ac.il/ GeneDis/Tables/APC/APC.html). Apart from these recurrent mutations, there is a high degree of allelic heterogeneity in the $A P C$ gene, giving rise to FAP disease. The vast majority of mutations found in the APC gene represent truncating 
mutations (caused by small deletions, 46\%; small insertions, $10 \%$; and nonsense mutations, 28\%). Missense mutations (3\%) and gross alterations (single- and multiexon deletions and duplications) (13\%) have also been reported (http://perso.curie. fr/Thierry.Soussi/APC.html; http://archive.uwcm.ac.uk/uwcm/ $\mathrm{mg} / \mathrm{hgmd} 0 . \mathrm{html}$; and http://life2.tau.ac.il/GeneDis/Tables/ APC/APC.html). Recent data suggest that gross alterations in the $A P C$ gene may have been underreported initially, with up to $20 \%$ of FAP families potentially carrying a gross alteration. Mutations contributing to classic FAP occur between exon 5 and the $5^{\prime}$ portion of exon 15 , whereas those associated with AFAP tend to cluster in the extreme $5^{\prime}$ portion of the gene (exons 1-4) and the $3^{\prime}$ portion of exon 15. There is limited correlation between the site of truncating mutations on the APC gene and the associated phenotype. Mutations that cluster in the region of codons 1250-1400 are associated with early-onset and severe polyposis, whereas mutations located $3^{\prime}$ to codon 1400 frequently correlate with osteomas, dental changes, and desmoids. This phenotype/genotype correlation is quite complex, which may be explained by variable interference of different mutant APC proteins with wild-type function, in addition to potential modifier genes. The new mutation rate for FAP has been reported to be as high as $20 \%{ }^{82}$ Although genetic risk can be evaluated through mutation testing, refined correlations between specific mutations and clinical phenotypes remain limited and do not provide any guidance for the clinical management of patients with FAP disease.

\subsection{2 p.I1307K Missense mutation in the APC gene}

This mutation does not lead to classic FAP, but it carries an increased $(10-20 \%)^{1}$ lifetime risk of developing colon cancer. It is estimated that $6 \%$ of all individuals of Ashkenazi Jewish ancestry carry the p.I1307K mutation. Genetic testing for the p.I1307K mutation is an option for individuals of Ashkenazi Jewish ancestry with a family history of colon cancer or polyps, a personal history of colon cancer or polyps, or a heightened concern for colon cancer. Early screening has been recommended for individuals who test positive for the p.I1307 missense mutation. ${ }^{83,84}$ The test is not appropriate for individuals who are not of Ashkenazi Jewish ancestry.

\subsection{3 p.E1317Q Missense mutation}

This mutation has been suggested to be associated with a predisposition to colon adenomas and/or colon cancer; however, there is no consensus, and the role of the p.E1317Q variant in colon cancer is uncertain. ${ }^{85}$

\subsection{Testing criteria}

Testing for FAP should be considered for individuals with the following ${ }^{12}$ :

1. Presence of 100 or more polyps;

2. Autosomal dominant inheritance;
3. Possible additional findings, such as congenital hypertrophy of retinal pigment epithelium, osteomas, supernumerary teeth, odontomas, desmoids, epidermoid cysts, duodenal and other small-bowel adenomas, gastric fundic gland polyps.

Testing for AFAP should be considered for individuals with the following:

1. Presence of $<100$ adenomas (average 30 polyps; Note: Individuals with 100 or more polyps occurring at older ages (35-40 years or older) may be found to have AFAP.);

2. Frequent right-sided distribution of polyps;

3. Adenomas and cancers at an age older than that for classic FAP and other gastrointestinal manifestations

\subsection{Algorithm for testing}

A suggested algorithm for FAP/AFAP syndrome testing is shown in Figure 2. It is recommended that FAP testing be performed using full sequencing of the $A P C$ gene. If no mutation is detected, then testing for large gene rearrangements should be performed.

\subsection{Sensitivity and specificity}

Comprehensive analysis of the entire $A P C$ gene is necessary for diagnostic testing of FAP. A mutation is detected in $~ 80 \%$ of patients with a clinical diagnosis of FAP, with DNA sequencing detecting $87 \%$ of point mutations and small insertions or deletions. ${ }^{86}$ The remaining $10-15 \%$ of mutations are gross deletions and duplications, which can be detected by MLPA, Southern blot, or real-time quantitative PCR analysis.

\subsection{Diagnostic versus predictive testing}

Molecular testing for mutations in the APC gene is used for diagnostic and presymptomatic testing. Positive results are considered diagnostic rather than predictive because the penetrance of a mutation is virtually $100 \%$.

\subsection{Prenatal testing}

This test can be used for prenatal diagnosis in both amniotic fluid cells and chorionic villus samples. Prior knowledge of the pathogenic familial mutation detected in the affected individual is required for prenatal testing. Several laboratories offer prenatal testing. Refer to GeneTests (http://www.genetests.org).

\subsection{Guidelines}

\subsubsection{Methodological considerations}

All general guidelines for PCR and DNA sequencing in the ACMG Standards and Guidelines for Clinical Genetics Laboratories apply (http://www.acmg.net). The following additional details are specific for $A P C$ gene testing. For this test, there are two valid methods with different strengths and weaknesses. 


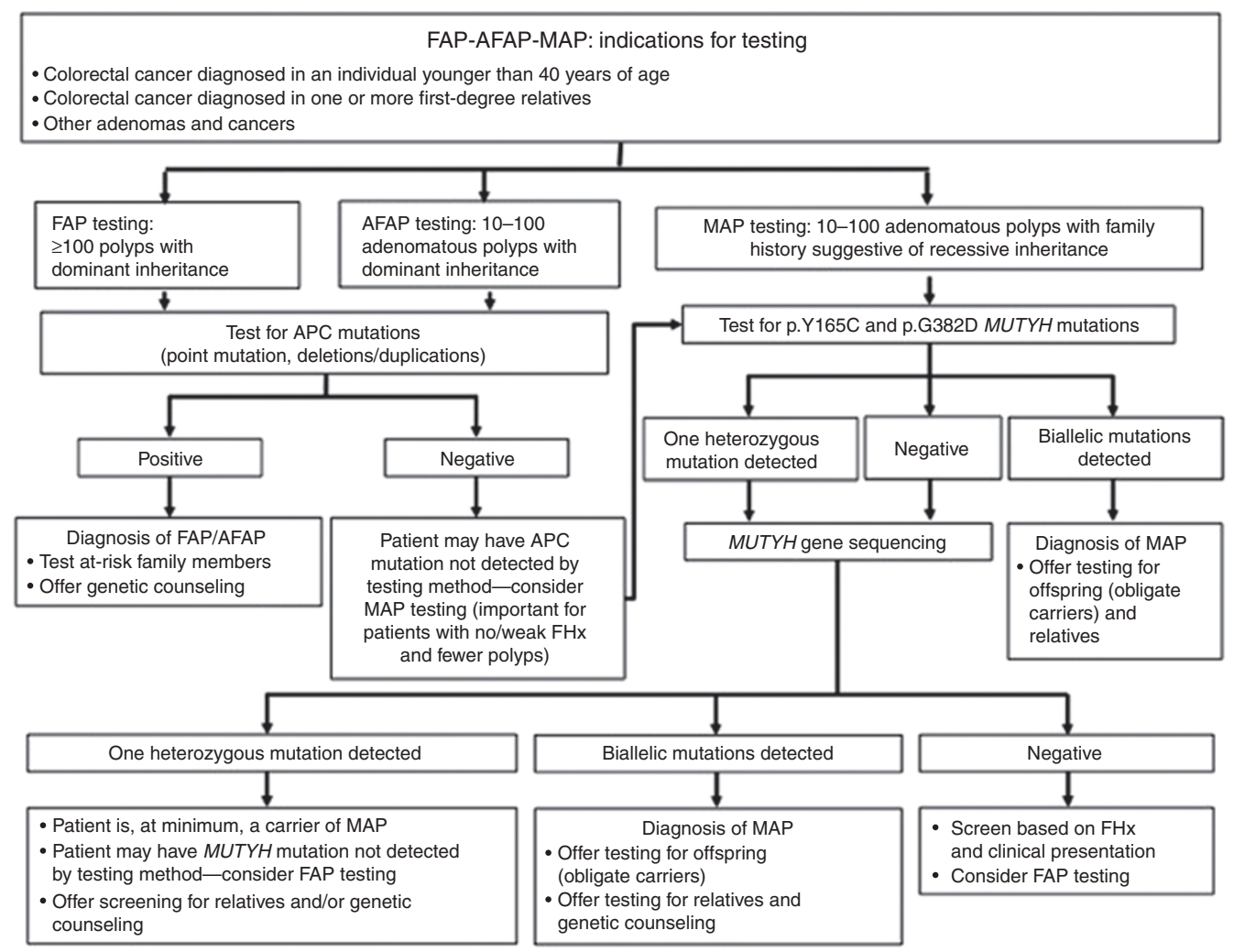

Figure 2 FAP-AFAP-MAP: indications of mapping. AFAP, attenuated adenomatous polyposis; FAP, familial adenomatous polyposis; FHx, family history; MAP, MYH-associated polyposis.

3.13.2 Detection of point mutations in the APC gene: methods 3.13.2.1 PCR method. The PCR method is described in section 2.13.7.1 (refs. 87-90).

3.13.2.2 Primer design. Primer design is described in section 2.13.7.2.

3.13.2.3 PCR product. PCR product is described in section 2.13.7.3.

3.13.2.4 Scanning. In the APC gene, the large majority of mutations are point mutations. Direct DNA sequencing of all 15 coding exons of the APC gene is considered the gold standard for mutation detection. However, many different approaches have been described to identify mutations in the $A P C$ gene. In the past, several clinical laboratories used the RNA-based protein truncation test, also known as the in vitro synthesized protein assay, which has a sensitivity ranging from 70 to $90 \%$, but the protein truncation test approach has disadvantages, including decreased RNA stability in blood lymphocytes, assay artifacts, and an inability to detect nontruncating mutations. In addition, not all laboratories actually characterize (i.e., sequence) the putative mutation implicated by a protein truncation test alteration. More recently, a DNA-based protein truncation test has been published, and some laboratories continue to use it. .1,92 $^{91}$ Other, less popular methods include scanning methods, followed by limited sequencing of aberrant fragments, as described in section 2.13.8. However, none of these methods has detection sensitivity as high as that of direct sequencing, which is a standard method in most clinical laboratories.
Refer to ACMG Standards and Guidelines for Clinical Genetics Laboratories, Section G19, for technical details.

3.13.2.5 Sanger sequencing. Sanger sequencing is described in section 2.13.9.1.

3.13.2.6 NGS. This process is described in section 2.13.9.2.

3.13.3 Methods for detection for of large rearrangements Gene-targeted CGH arrays can also be used, as described in section 2.13.10.

\subsubsection{Interpretation}

Refer to section 2.14.3 for interpretation.

\section{MYH-ASSOCIATED POLYPOSIS}

$\mathrm{MYH}$-associated polyposis (MAP) is caused by biallelic mutations in the MUTYH gene. It is characterized by an increased lifetime risk of CRC. The penetrance of CRC in individuals with biallelic germ line MUTYH mutations is high but incomplete at age 60 years. MAP is estimated to account for $0.7 \%$ of all CRC cases and up to $2 \%$ of familial or early-onset CRC cohorts in which affected individuals have a low number $(<15-20)$ of adenomas. ${ }^{93-96}$

\subsection{Gene symbol/chromosome locus, OMIM, and transcript number \\ MUTYH (OMIM 604933 (608456), NM_001048171.1) is the gene symbol recognized by the HUGO nomenclature com- mittee (http://www.gene.ucl.ac.uk/nomenclature/). The gene}


has also been referred to as $M Y H$. The chromosome locus is 1p32.1-1p34.3.

\subsection{Other loci}

None.

\subsection{Brief clinical description}

The MUTYH gene has been implicated in predisposition to the multiple adenoma phenotype. MAP has been described as an autosomal recessive form of FAP associated with susceptibility to CRC. ${ }^{95,97}$ MAP is characterized by multiple colorectal adenomas and a high risk of CRC. The polyp burden of individuals affected with MAP is variable, and although the data are limited, current evidence suggests that biallelic mutations can be found in up to $30 \%$ of patients with 15-100 adenomas and in $\sim 7 \%$ of patients with $>100$ adenomas. ${ }^{3}$ Biallelic mutations have been identified in patients with no detectable polyposis.

\subsection{Mode of inheritance}

Given the autosomal recessive nature of the disease, family histories are usually unremarkable. With the absence of family history in MAP and the high rate of de novo mutations in AFAP and FAP, analysis of both MUTYH and APC gene mutations should be considered for patients with multiple adenomatous polyps.

\subsection{Gene description/normal gene product}

The human MutY homolog, MUTYH, is a human base excision repair gene involved in preventing 8-oxo-dG-induced mutagenesis. MUTYH contains 16 exons encoding a protein of 535 amino acids. MUTYH, an adenine-specific DNA glycosylase, removes adenine residues mispaired with 8-oxo-dG or guanine.

\subsection{Mutational mechanism/abnormal gene product}

MAP is caused by the deficiency or absence of the MUTYH protein. MUTYH repairs DNA by removing adenine residues that are mispaired with 8-oxoguanine during replication of oxidized DNA. Tumors from patients with biallelic MUTYH mutations have an excess of somatic mutations (guanine-tothymine transversions) in the APC gene.

\subsection{MYH transcript and mutation nomenclature}

Multiple transcripts are produced from MUTYH, which has complicated the nomenclature used to describe mutations identified in the gene. The two major transcripts are hMYHol (NM_012222.2) and hMYHo3 (NM_001048171.1), encoding polypeptides of 546 and 535 amino acids, respectively. The hMYHa3 transcript is 33 nucleotides shorter than the hMYHo1 transcript and results from alternative splicing of exon 3 , which eliminates 11 amino acids from the $5^{\prime}$ end of exon 3 (GMIAECPGAPA). All other codons, and therefore amino acids, are identical between the two isoforms. Although most publications use the hMYH $\alpha 3$ variant when naming mutations, some reports use the full-length transcript (hMYH $\alpha 1)$. When reporting results for $M U T Y H$ testing, or when comparing reports from different laboratories, it is imperative to note which transcript has been used to name the alteration(s) found in the gene. Table 2 illustrates this concept with the two most common alterations and the nomenclature used to describe them by isoform.

\subsection{Mutation spectrum, prevalence, and ethnic association} of common mutations

Most major ethnic groups seem to have mutations in the MUTYH gene. There appear to be a number of founder mutations common to specific ethnic groups, such as p.Y90X in Pakistani patients and p.E499X in Indian patients; several studies have examined control groups for the two common missense mutations, with a prevalence of $0-2 \%$ established in different ethnic populations. Other specific mutations have been reported in the Japanese, Italian, Portuguese, and Finnish populations. ${ }^{1,98-100}$

Although a number of mutations in the MUTYH gene have been documented, two missense mutations, p.Y165C and p.G382D, account for $70-80 \%$ of mutant alleles in the Northern European population, with a third mutation, 1395delGGA, accounting for $\sim 25 \%$ of mutant alleles in persons of a Southern European (Mediterranean) background. ${ }^{101}$ The common missense mutations in MUTYH, p.Y165C and p.G382D, have a well-established effect on glycosylase function in experimental systems. More recently, additional missense changes have been reported. Deletions and frameshift and nonsense mutations that are likely to be pathogenic have also been reported.

\subsection{Testing criteria}

Testing for MAP should be considered for individuals with the following criteria:

1. CRC diagnosed in an individual younger than 40 years of age;

2. The presence of 10 or more adenomatous polyps in the absence of a germ line APC gene mutation;

3. 3.Family history of colon cancer consistent with an autosomal recessive inheritance. This includes colon cancers with or without polyps.

\subsection{Algorithm for testing}

A suggested algorithm for MAP syndrome testing is shown in Figure 2. It is recommended that testing for MAP be first performed for the two most common mutations, p.Y165C and p.G382D, before proceeding to full sequencing of the MUTYH gene. If one mutation is detected, then full MUTYH sequencing should be performed. If the two common mutations are not detected, then full sequencing of the MUTYH gene can be considered depending on the clinical presentation and family history.

Table 2 Isoforms of MUTYH and mutation nomenclature for the common mutations

\begin{tabular}{|c|c|}
\hline hMYH $\alpha 1$ & hMYH $\alpha 3$ \\
\hline p.Y176C & p.Y165C \\
\hline p.G393D & p.G382D \\
\hline
\end{tabular}




\subsection{Sensitivity and specificity}

Targeted mutation analysis for p.Y165C and p.G382D covers $\sim 80 \%$ of mutations in the MUTYH gene in the North European and Caucasian population. Sequence analysis of the entire coding region of the MUTYH gene can detect up to $99 \%$ of mutations. Heterozygous single-exon and multiexon deletions and duplications cannot be detected by Sanger sequencing. ${ }^{95,97,101-104}$

\subsection{Diagnostic versus predictive testing}

Molecular testing for mutations in the MUTYH gene is used for confirmative diagnosis and carrier detection. More than 100 mutations have been described in the MUTYH gene (Human Gene Mutation Database, http://www.hgmd.org). If heterozygosity for only one of the common mutations is detected in a diagnostic case or no mutation is detected, sequencing of the MUTYH gene should be considered.

\subsection{Carrier testing}

Approximately $1-2 \%$ of the general population is predicted to carry a MUTYH mutation. Individuals who are heterozygous for MUTYH mutations may be at risk-depending on the status of their reproductive partner-of having a child with this recessive condition.

\subsection{Guidelines}

4.14.1 Definition of mutation categories

The majority of the mutations detected in the MUTYH gene are point mutations, which include nonsense, missense, and small insertion/deletion mutations. Only one intragenic deletion has been described in the MUTYH gene. ${ }^{105}$

4.14.2 Methodological considerations

All general guidelines for PCR and DNA sequencing in the ACMG Standards and Guidelines for Clinical Genetics Laboratories apply (http://www.acmg.net). The following additional details are specific for MUTYH gene testing. For this test, there are two valid methods with different strengths and weaknesses.

4.14.3 Detection of point mutations in the MUTYH gene: methods

4.14.3.1 PCR method. The PCR method is described in section 2.13.7.1 (refs. 87-90).

4.14.3.2 Primer design. Primer design is described in section 2.13.7.2.

4.14.3.3 PCR product. PCR product is described in section 2.13.7.3.

4.14.3.4 Targeted detection of p.Y165C and p.G382D. Restriction-fragment-length polymorphism is a PCR/restriction enzyme digestion-based technique that allows for the discrimination of gene variants by producing genotype-specific banding patterns on native agarose or acrylamide gels; it is the most commonly used method for detection of the p.Y165C and p.G382D mutations. Briefly, the region surrounding the mutation to be interrogated is amplified by PCR. The PCR product is then digested with a restriction enzyme,
BseXI or Bgl II, specific for the p.Y165C and G382 mutations, respectively. The digested products are then electrophoresed on a native polyacrylamide gel to detect the mutant allele. The digested product produces a specific pattern if only wildtype sequence is present and a different but specific pattern if only mutant sequence is present. A properly designed assay must allow for the recognition of heterozygous individuals as well. A restriction-fragment-length polymorphism (RFLP) gel for mutation detection of p.Y165C for heterozygous samples using the BseXI and Bgl II restriction enzymes gives fragments of 105, 83, and $61 \mathrm{bp}$, and for homozygous samples, it yields fragments of 105 and $61 \mathrm{bp}$.

4.13.3.5 Other technologies. Other technologies, such as denaturing high-pressure liquid chromatography, pyrosequencing, and allele-specific primer extension, can also be used for detecting p.Y165C and p.G382D mutations.

4.13.3.6 Limitations. Most of the targeted methods are extremely sensitive and can detect $>99 \%$ of the mutations in the MUTYH gene. The presence of unknown SNPs in close proximity to the mutation may lead to a false-negative result.

4.13.3.7 Sanger sequencing. Sanger sequencing is described in section 2.13.9.1.

4.13.3.8 NGS. This process is described in section 2.13.9.2.

4.14.4 Methods for detection of large gene rearrangements No large deletions or duplications have been reported in the MUTYH gene.

\subsubsection{Interpretation}

Refer to section 2.14 .3 for interpretation.

\section{SAMPLE REPORTS}

Sample reports are available in the Supplementary Appendix online. Sample report templates are also available in publications by Scheuner et al. ${ }^{106,107}$

\section{SUPPLEMENTARY MATERIAL}

Supplementary material is linked to the online version of the paper at http://www.nature.com/gim

\section{ACKNOWLEDGMENT}

These technical standards and guidelines were approved by the ACMG Board of Directors on 20 May 2013.

\section{DISCLOSURE}

A.G., M.F., R.M., W.S., and M.H. are employed by fee-for-service laboratories performing next-generation sequencing. Two individuals serve on advisory boards or in other capacities for companies providing next-generation sequencing services (M.H.: GenomeQuest, RainDance, Ingenuity, Oxford Gene Technology, and InVitae; M.F.: SoftGenetics and SVBio). The University of Utah and W.S. (and two coinventors) have a pending patent to use BRAF mutation status in microsatellite-stable tumors as a predictor of poor prognosis. The patent rights have been licensed by Ventana. 


\section{REFERENCES}

1. Goodenberger M, Lindor NM. Lynch syndrome and MYH-associated polyposis: review and testing strategy. J Clin Gastroentero/ 2011;45:488-500.

2. Markowitz SD, Bertagnolli MM. Molecular origins of cancer: Molecular basis of colorectal cancer. N Engl J Med 2009;361:2449-2460.

3. Peterlongo P, Mitra N, Sanchez de Abajo A, et al. Increased frequency of disease-causing MYH mutations in colon cancer families. Carcinogenesis 2006:27:2243-2249.

4. Coates R, Williams M, Melillo S, Gudgeon J. Genetic testing for lynch syndrome in individuals newly diagnosed with colorectal cancer to reduce morbidity and mortality from colorectal cancer in their relatives. PLoS Curr 2011;3:RRN1246.

5. Stoffel EM. Lynch Syndrome/Hereditary Non-polyposis Colorectal Cancer (HNPCC). Minerva Gastroenterol Dietol p.2010;56:45-53.

6. Evaluation of Genomic Applications in Practice and Prevention (EGAPP) Working Group. Recommendations from the EGAPP Working Group: genetic testing strategies in newly diagnosed individuals with colorectal cancer aimed at reducing morbidity and mortality from Lynch syndrome in relatives. Genet Med 2009;11:35-41.

7. Palomaki GE, McClain MR, Melillo S, Hampel HL, Thibodeau SN. EGAPP supplementary evidence review: DNA testing strategies aimed at reducing morbidity and mortality from Lynch syndrome. Genet Med 2009;11:42-65.

8. Steinhagen E, Shia J, Markowitz AJ, et al. Systematic immunohistochemistry screening for Lynch syndrome in early age-of-onset colorectal cancer patients undergoing surgical resection. J Am Coll Surg 2012;214:61-67.

9. Walsh J, Arora M, Hosenfeld C, Ladabaum U, Kuppermann M, Knight SJ. Preferences for genetic testing to identify hereditary colorectal cancer: perspectives of high-risk patients, community members, and clinicians. J Cancer Educ 2012:27:112-119.

10. Ladabaum U, Wang G, Terdiman J, et al. Strategies to identify the Lynch syndrome among patients with colorectal cancer: a cost-effectiveness analysis. Ann Intern Med 2011;155:69-79.

11. Jackson GL, Zullig LL, Zafar SY, et al. Using NCCN clinical practice guidelines in oncology to measure the quality of colorectal cancer care in the veterans health administration. J Nat/ Compr Canc Netw 2013;11:431-441.

12. Benson $A B$ 3rd, Bekaii-Saab T, Chan E, et al. Metastatic colon cancer, version 3.2013: featured updates to the NCCN Guidelines. J Natl Compr Canc Netw 2013;11:141-52; quiz 152

13. Poonacha TK, Go RS. Level of scientific evidence underlying recommendations arising from the National Comprehensive Cancer Network clinical practice guidelines. J Clin Oncol 2011;29:186-191.

14. Bellcross CA, Bedrosian SR, Daniels E, et al. Implementing screening for Lynch syndrome among patients with newly diagnosed colorectal cancer: summary of a public health/clinical collaborative meeting. Genet Med 2012;14:152-162.

15. Singh MM, Singh E, Miller H, Strum WB, Coyle W. Colorectal cancer screening in women with endometrial cancer: are we following the guidelines? J Gastrointest Cancer 2012;43:190-195.

16. Kotake K. [Comparison between JSCCR and NCCN guidelines for the treatment of colorectal cancer]. Nippon Rinsho 2011;69(suppl 3):242-246.

17. Boland CR, Thibodeau SN, Hamilton SR, et al. A National Cancer Institute Workshop on Microsatellite Instability for cancer detection and familial predisposition: development of international criteria for the determination of microsatellite instability in colorectal cancer. Cancer Res 1998;58:5248-5257.

18. Raedle J, Trojan J, Brieger A, et al. Bethesda guidelines: relation to microsatellite instability and MLH1 promoter methylation in patients with colorectal cancer. Ann Intern Med 2001;135(8 Pt 1):566-576.

19. Wüllenweber HP, Sutter $C$, Autschbach F, et al. Evaluation of Bethesda guidelines in relation to microsatellite instability. Dis Colon Rectum 2001;44:1281-1289.

20. Vasen HF, Mecklin JP, Khan PM, Lynch HT. The International Collaborative Group on Hereditary Non-Polyposis Colorectal Cancer (ICG-HNPCC). Dis Colon Rectum 1991;34:424-425.

21. Vasen HF, Mecklin JP, Khan PM, Lynch HT. The International Collaborative Group on HNPCC. Anticancer Res 1994;14(4B):1661-1664.

22. Vasen HF. Review article: The Lynch syndrome (hereditary nonpolyposis colorectal cancer). Aliment Pharmacol Ther 2007;26(suppl 2):113-126.

23. Umar A, Boland CR, Terdiman JP, et al. Revised Bethesda Guidelines for hereditary nonpolyposis colorectal cancer (Lynch syndrome) and microsatellite instability. J Natl Cancer Inst 2004;96:261-268.

24. Umar A, Risinger Jl, Hawk ET, Barrett JC. Testing guidelines for hereditary nonpolyposis colorectal cancer. Nat Rev Cancer 2004;4:153-158.

25. Win AK, Jenkins MA, Buchanan DD, et al. Determining the frequency of de novo germline mutations in DNA mismatch repair genes. J Med Genet 2011;48:530-534.
26. Felton KE, Gilchrist DM, Andrew SE. Constitutive deficiency in DNA mismatch repair: is it time for Lynch III? Clin Genet 2007;71:499-500.

27. Felton KE, Gilchrist DM, Andrew SE. Constitutive deficiency in DNA mismatch repair. Clin Genet 2007;71:483-498.

28. De Vos M, Hayward BE, Picton S, Sheridan E, Bonthron DT. Novel PMS2 pseudogenes can conceal recessive mutations causing a distinctive childhood cancer syndrome. Am J Hum Genet 2004;74:954-964.

29. Lynch PM. The hMSH2 and hMLH1 genes in hereditary nonpolyposis colorectal cancer. Surg Oncol Clin N Am 2009;18:611-624.

30. Genuardi M, Anti M, Capozzi E, et al. MLH1 and MSH2 constitutional mutations in colorectal cancer families not meeting the standard criteria for hereditary nonpolyposis colorectal cancer. Int J Cancer 1998;75:835-839.

31. Giráldez MD, Balaguer F, Bujanda L, et al. MSH6 and MUTYH deficiency is a frequent event in early-onset colorectal cancer. Clin Cancer Res 2010;16:54025413.

32. Duraturo F, Liccardo R, Cavallo A, De Rosa M, Grosso M, Izzo P. Association of low-risk MSH3 and MSH2 variant alleles with Lynch syndrome: probability of synergistic effects. Int J Cancer 2011;129:1643-1650.

33. Nicolaides NC, Papadopoulos N, Liu B, et al. Mutations of two PMS homologues in hereditary nonpolyposis colon cancer. Nature 1994;371:75-80.

34. Talseth-Palmer BA, McPhillips M, Groombridge C, Spigelman A, Scott RJ MSH6 and PMS2 mutation positive Australian Lynch syndrome families: novel mutations, cancer risk and age of diagnosis of colorectal cancer. Hered Cancer Clin Pract 2010;8:5.

35. Yuan ZQ, Wong N, Foulkes WD, et al. A missense mutation in both $\mathrm{hMSH} 2$ and APC in an Ashkenazi Jewish HNPCC kindred: implications for clinical screening. J Med Genet 1999;36:790-793.

36. Pérez-Carbonell L, Ruiz-Ponte C, Guarinos C, et al. Comparison between universal molecular screening for Lynch syndrome and revised Bethesda guidelines in a large population-based cohort of patients with colorectal cancer. Gut 2012;61:865-872.

37. Poulogiannis G, Frayling IM, Arends MJ. DNA mismatch repair deficiency in sporadic colorectal cancer and Lynch syndrome. Histopathology 2010;56:167179.

38. Bartley AN, Luthra R, Saraiya DS, Urbauer DL, Broaddus RR. Identification of cancer patients with Lynch syndrome: clinically significant discordances and problems in tissue-based mismatch repair testing. Cancer Prev Res (Phila) 2012;5:320-327.

39. Plaschke J, Krüger S, Dietmaier W, et al.; German HNPCC Consortium. Eight novel MSH6 germline mutations in patients with familial and nonfamilial colorectal cancer selected by loss of protein expression in tumor tissue. Hum Mutat 2004;23:285.

40. Plaschke J, Linnebacher M, Kloor M, et al. Compound heterozygosity for two MSH6 mutations in a patient with early onset of HNPCC-associated cancers, but without hematological malignancy and brain tumor. Eur J Hum Genet 2006;14:561-566

41. Kim YH, Kakar S, Cun L, Deng G, Kim YS. Distinct CpG island methylation profiles and BRAF mutation status in serrated and adenomatous colorectal polyps. Int J Cancer 2008;123:2587-2593.

42. Kim YS, Deng G. Epigenetic changes (aberrant DNA methylation) in colorectal neoplasia. Gut Liver 2007;1:1-11.

43. Deng G, Bell I, Crawley S, et al. BRAF mutation is frequently present in sporadic colorectal cancer with methylated hMLH1, but not in hereditary nonpolyposis colorectal cancer. Clin Cancer Res 2004;10(1 Pt 1):191-195.

44. Deng DJ, Zhou J, Zhu BD, Ji JF, Harper JC, Powell SM. Silencing-specific methylation and single nucleotide polymorphism of hMLH1 promoter in gastric carcinomas. World J Gastroenterol 2003;9:26-29.

45. Deng G, Peng E, Gum J, Terdiman J, Sleisenger M, Kim YS. Methylation of hMLH1 promoter correlates with the gene silencing with a region-specific manner in colorectal cancer. Br J Cancer 2002;86:574-579.

46. Deng D, Deng G, Smith MF, et al. Simultaneous detection of CpG methylation and single nucleotide polymorphism by denaturing high performance liquid chromatography. Nucleic Acids Res 2002;30:E13.

47. Deng D, Deng G, Lü Y. [Analysis of the methylation in CpG island by denaturing high-performance liquid chromatography]. Zhonghua Yi Xue Za Zhi 2001;81:158-161.

48. Deng G, Chen A, Pong E, Kim YS. Methylation in hMLH1 promoter interferes with its binding to transcription factor $C B F$ and inhibits gene expression. Oncogene 2001;20:7120-7127.

49. Deng G, Chen A, Hong J, Chae HS, Kim YS. Methylation of CpG in a small region of the hMLH1 promoter invariably correlates with the absence of gene expression. Cancer Res 1999;59:2029-2033. 
50. Rahner N, Friedrichs $N$, Steinke $V$, et al. Coexisting somatic promoter hypermethylation and pathogenic MLH1 germline mutation in Lynch syndrome. J Pathol 2008:214:10-16.

51. Valle L, Carbonell P, Fernandez V, et al. MLH1 germline epimutations in selected patients with early-onset non-polyposis colorectal cancer. Clin Genet 2007;71:232-237.

52. Niessen RC, Hofstra RM, Westers $H$, et al. Germline hypermethylation of MLH1 and EPCAM deletions are a frequent cause of Lynch syndrome. Genes Chromosomes Cancer 2009:48:737-744.

53. Parsons MT, Buchanan DD, Thompson B, Young JP, Spurdle AB. Correlation of tumour BRAF mutations and MLH1 methylation with germline mismatch repair (MMR) gene mutation status: a literature review assessing utility of tumour features for MMR variant classification. J Med Genet 2012:49:151-157.

54. Loughrey MB, Waring PM, Tan A, et al. Incorporation of somatic BRAF mutation testing into an algorithm for the investigation of hereditary non-polyposis colorectal cancer. Fam Cancer 2007;6:301-310.

55. Bonadona V, Bonaïti B, Olschwang S, et al.; French Cancer Genetics Network. Cancer risks associated with germline mutations in MLH1, MSH2, and MSH6 genes in Lynch syndrome. JAMA 2011;305:2304-2310.

56. Stoffel E, Mukherjee B, Raymond VM, et al. Calculation of risk of colorectal and endometrial cancer among patients with Lynch syndrome. Gastroenterology 2009;137:1621-1627.

57. Stoffel EM, Chittenden A. Genetic testing for hereditary colorectal cancer: challenges in identifying, counseling, and managing high-risk patients. Gastroenterology 2010;139:1436-41, 1441.e1.

58. Shi SR, Datar R, Liu C, et al. DNA extraction from archival formalin-fixed, paraffin-embedded tissues: heat-induced retrieval in alkaline solution. Histochem Cell Biol 2004;122:211-218.

59. Hitchins MP, Ward RL. Erasure of MLH1 methylation in spermatozoaimplications for epigenetic inheritance. Nat Genet 2007;39:1289.

60. Hitchins MP, Ward RL. MLH1 germ-line epimutations: is there strong evidence of its inheritance? Gastroenterology 2008;134:359-360.

61. Hitchins MP, Ward RL. Constitutional (germline) MLH1 epimutation as an aetiological mechanism for hereditary non-polyposis colorectal cancer. J Med Genet 2009;46:793-802.

62. Koh DC, Luchtefeld MA, Kim DG, Attal H, Monroe T, Ingersoll K. Microsatellite instability and MLH1 hypermethylation - incidence and significance in colorectal polyps in young patients. Colorectal Dis 2007:9:521-526.

63. Ogino S, Kawasaki T, Brahmandam M, et al. Precision and performance characteristics of bisulfite conversion and real-time PCR (MethyLight) for quantitative DNA methylation analysis. J Mol Diagn 2006;8:209-217.

64. Fukushima T, Katayama Y, Watanabe T, et al. Promoter hypermethylation of mismatch repair gene hMLH1 predicts the clinical response of malignant astrocytomas to nitrosourea. Clin Cancer Res 2005;11:1539-1544.

65. Frazier ML, Sinicrope $F A$, Amos $\mathrm{Cl}$, et al. Loci for efficient detection of microsatellite instability in hereditary non-polyposis colorectal cancer. Oncol Rep 1999:6:497-505.

66. Ebinger M, Sotlar K, Weber A, Bock CT, Bültmann BD, Kandolf R. Simplified detection of microsatellite instability in colorectal cancer without the need for corresponding germline DNA analysis. J Clin Patho/ 2006;59:1114-1115.

67. Buhard O, Suraweera N, Lectard A, Duval A, Hamelin R. Quasimonomorphic mononucleotide repeats for high-level microsatellite instability analysis. Dis Markers 2004:20:251-257.

68. Suraweera N, Duval A, Reperant M, et al. Evaluation of tumor microsatellite instability using five quasimonomorphic mononucleotide repeats and pentaplex PCR. Gastroenterology 2002;123:1804-1811.

69. Pyatt R, Chadwick RB, Johnson CK, Adebamowo C, de la Chapelle A, Prior TW. Polymorphic variation at the BAT-25 and BAT-26 loci in individuals of African origin. Implications for microsatellite instability testing. Am J Pathol 1999;155:349-353.

70. Søreide K. Molecular testing for microsatellite instability and DNA mismatch repair defects in hereditary and sporadic colorectal cancers-ready for prime time? Tumour Biol 2007:28:290-300.

71. Hegde M, Blazo M, Chong B, Prior T, Richards C. Assay validation for identification of hereditary nonpolyposis colon cancer-causing mutations in mismatch repair genes MLH1, MSH2, and MSH6. J Mol Diagn 2005;7:525-534.

72. Hendriks YM, Jagmohan-Changur S, van der Klift HM, et al. Heterozygous mutations in PMS2 cause hereditary nonpolyposis colorectal carcinoma (Lynch syndrome). Gastroenterology 2006;130:312-322.

73. Richards CS, Bale S, Bellissimo DB, et al.; Molecular Subcommittee of the ACMG Laboratory Quality Assurance Committee. ACMG recommendations for standards for interpretation and reporting of sequence variations: Revisions 2007. Genet Med 2008;10:294-300.

74. Maddalena A, Bale S, Das S, Grody W, Richards S; ACMG Laboratory Quality Assurance Committee. Technical standards and guidelines: molecular genetic testing for ultra-rare disorders. Genet Med 2005;7:571-583.

75. Tayeh MK, Chin EL, Miller VR, Bean LJ, Coffee B, Hegde M. Targeted comparative genomic hybridization array for the detection of single- and multiexon gene deletions and duplications. Genet Med 2009;11:232-240.

76. Rumilla K, Schowalter KV, Lindor NM, et al. Frequency of deletions of EPCAM (TACSTD1) in MSH2-associated Lynch syndrome cases. J Mol Diagn 2011:13:93-99.

77. Lynch HT, Lynch JF, Snyder CL, Riegert-Johnson D. EPCAM deletions, Lynch syndrome, and cancer risk. Lancet Oncol 2011;12:5-6.

78. Knudson A. Alfred Knudson and his two-hit hypothesis. (Interview by Ezzie Hutchinson). Lancet Onco/ 2001:2:642-645.

79. White RL. Colon cancer. Molecular biology of the APC protein. Pathol Biol 1997:45:240-244.

80. Umar A, Viner JL, Hawk ET. The future of colon cancer prevention. Ann N Y Acad Sci 2001;952:88-108.

81. Claes K, Dahan K, Tejpar S, et al. The genetics of familial adenomatous polyposis (FAP) and MutYH-associated polyposis (MAP). Acta Gastroenterol Belg 2011;74:421-426

82. Hes FJ, Nielsen M, Bik EC, et al. Somatic APC mosaicism: an underestimated cause of polyposis coli. Gut 2008;57:71-76.

83. Rennert G, Almog R, Tomsho LP, et al. Colorectal polyps in carriers of the APC I1307K polymorphism. Dis Colon Rectum 2005;48:2317-2321.

84. Shtoyerman-Chen R, Friedman E, Figer A, et al. The I1307K APC polymorphism: prevalence in non-Ashkenazi Jews and evidence for a founder effect. Genet Test 2001:5:141-146.

85. Popat S, Stone J, Coleman G, et al. Prevalence of the APC E1317Q variant in colorectal cancer patients. Cancer Lett 2000;149:203-206.

86. Grover S, Kastrinos F, Steyerberg EW, et al. Prevalence and phenotypes of APC and MUTYH mutations in patients with multiple colorectal adenomas. JAMA 2012;308:485-492

87. Castellsagué E, González $\mathrm{S}$, Nadal $\mathrm{M}$, et al. Detection of APC gene deletions using quantitative multiplex PCR of short fluorescent fragments. Clin Chem 2008:54:1132-1140.

88. De la Fuente MK, Alvarez KP, Letelier AJ. et al. Mutational screening of the APC gene in Chilean families with familial adenomatous polyposis: nine novel truncating mutations. Dis Colon Rectum 2007;50:2142-2148.

89. Gavert N, Yaron Y, Naiman T, et al. Molecular analysis of the APC gene in 71 Israeli families: 17 novel mutations. Hum Mutat 2002;19:664.

90. De Filippo C, Luceri C, Caderni G, et al. Mutations of the APC gene in human sporadic colorectal cancers. Scand J Gastroentero/ 2002;37:1048-1053.

91. Diehl F, Traverso G. High-throughput in vitro translation. Discov Med 2003;3:44-45.

92. Gite S, Lim M, Carlson R, Olejnik J, Zehnbauer B, Rothschild K. A highthroughput nonisotopic protein truncation test. Nat Biotechnol 2003;21:194197

93. Leite JS, Isidro G, Martins M, et al. Is prophylactic colectomy indicated in patients with MYH-associated polyposis? Colorectal Dis 2005;7:327-331.

94. Isidro $G$, Laranjeira F, Pires $A$, et al. Germline MUTYH (MYH) mutations in Portuguese individuals with multiple colorectal adenomas. Hum Mutat 2004;24:353-354

95. Wang L, Baudhuin LM, Boardman LA, et al. MYH mutations in patients with attenuated and classic polyposis and with young-onset colorectal cancer without polyps. Gastroenterology 2004;127:9-16.

96. Sieber OM, Lipton L, Crabtree M, et al. Multiple colorectal adenomas, classic adenomatous polyposis, and germ-line mutations in MYH. N Engl J Med 2003;348:791-799

97. Venesio T, Molatore S, Cattaneo F, Arrigoni A, Risio M, Ranzani GN. High frequency of MYH gene mutations in a subset of patients with familial adenomatous polyposis. Gastroenterology 2004;126:1681-1685.

98. Colebatch A, Hitchins M, Williams R, Meagher A, Hawkins NJ, Ward RL. The role of MYH and microsatellite instability in the development of sporadic colorectal cancer. Br J Cancer 2006;95:1239-1243.

99. Al-Tassan N, Eisen T, Maynard J, et al. Inherited variants in MYH are unlikely to contribute to the risk of lung carcinoma. Hum Genet 2004;114:207-210.

100. Al-Tassan N, Chmiel NH, Maynard J, et al. Inherited variants of MYH associated with somatic $\mathrm{G}: \mathrm{C} \rightarrow \mathrm{T}$ :A mutations in colorectal tumors. Nat Genet 2002:30:227-232. 
101. Gismondi V, Meta M, Bonelli L, et al. Prevalence of the Y165C, G382D and 1395del GGA germline mutations of the MYH gene in Italian patients with adenomatous polyposis coli and colorectal adenomas. Int J Cancer 2004;109:680-684.

102. Croitoru ME, Cleary SP, Di Nicola N, et al. Association between biallelic and monoallelic germline MYH gene mutations and colorectal cancer risk. J Natl Cancer Inst 2004;96:1631-1634.

103. Enholm S, Hienonen T, Suomalainen $A$, et al. Proportion and phenotype of MYH-associated colorectal neoplasia in a population-based series of Finnish colorectal cancer patients. Am J Patho/ 2003:163:827-832.

104. Jones S, Emmerson P, Maynard J, et al. Biallelic germline mutations in MYH predispose to multiple colorectal adenoma and somatic $\mathrm{G}: \mathrm{C} \rightarrow \mathrm{T}$ :A mutations. Hum Mol Genet 2002;11:2961-2967.
105. Buchanan D, Young J. A perspective on bi-allelic MUTYH mutations in patients with hyperplastic polyposis syndrome. Gastroenterology 2009;136:24072408.

106. Scheuner MT, Edelen MO, Hilborne LH, Lubin IM; RAND Molecular Genetic Test Report Advisory Board. Effective communication of molecular genetic test results to primary care providers. Genet Med 2013;15:444449.

107. Scheuner MT, Hilborne L, Brown J, Lubin IM; members of the RAND Molecular Genetic Test Report Advisory Board. A report template for molecular genetic tests designed to improve communication between the clinician and laboratory. Genet Test Mol Biomarkers 2012;16: 761-769. 